\title{
OPEN ANGPTL3 gene variants in subjects with familial combined hyperlipidemia
}

\author{
A. M. Bea ${ }^{1}$, E. Franco-Marín ${ }^{1}$, V. Marco-Benedi ${ }^{1,2}$, E. Jarauta ${ }^{1,2}$, I. Gracia-Rubio ${ }^{1}$, \\ A. Cenarro ${ }^{1,3 \bowtie}$, F. Civeira ${ }^{1,2}$ \& I. Lamiquiz-Moneo ${ }^{1,2}$
}

Angiopoietin-like 3 (ANGPTL3) plays an important role in lipid metabolism in humans. Loss-offunction variants in ANGPTL3 cause a monogenic disease named familial combined hypolipidemia. However, the potential contribution of ANGPTL3 gene in subjects with familial combined hyperlipidemia (FCHL) has not been studied. For that reason, the aim of this work was to investigate the potential contribution of ANGPTL3 in the aetiology of FCHL by identifying gain-of-function (GOF) genetic variants in the ANGPTL3 gene in FCHL subjects. ANGPTL3 gene was sequenced in 162 unrelated subjects with severe FCHL and 165 normolipemic controls. Pathogenicity of genetic variants was predicted with PredictSNP2 and FruitFly. Frequency of identified variants in FCHL was compared with that of normolipemic controls and that described in the 1000 Genomes Project. No GOF mutations in ANGPTL3 were present in subjects with FCHL. Four variants were identified in FCHL subjects, showing a different frequency from that observed in normolipemic controls: c.607-109T $>C$, c.607-47_607-46delGT, c.835+41C>A and c.*52_*60del. This last variant, c.*52_*60del, is a microRNA associated sequence in the $3^{\prime} U T R$ of $A N G P T L 3$, and it was present 2.7 times more frequently in normolipemic controls than in FCHL subjects. Our research shows that no GOF mutations in ANGPTL3 were found in a large group of unrelated subjects with FCHL.

Angiopoietin-like 3 (ANGPTL3) is a $70 \mathrm{kDa}$-secreted (54 kDa before glycosylation) protein, mainly expressed in the liver, discovered by Conklin et al. in $1999^{1}$. ANGPTL3 is an endogenous inhibitor of lipoprotein lipase $(\mathrm{LPL})$ and endothelial lipase (EL) ${ }^{2,3}$. Different studies in families with hypolipemia and in general population have reported that loss-of-function (LOF) variants in ANGPTL3 gene are associated with decreased plasma levels of triglycerides (TG), low-density lipoprotein cholesterol (LDLc) and high-density lipoprotein cholesterol (HDLc) ${ }^{4}$. The N-terminal domain of ANGPTL3 containing residues from 17 to 207 is responsible for the increased plasma TG levels in mice. Loss of this region prevents the inhibition of LPL ${ }^{5}$ and EL ${ }^{3}$ by ANGPTL3. Recently, the inhibition of ANGPTL3 with a human monoclonal antibody against ANGPTL3 (evinacumab) in dyslipidemic mice and in healthy volunteers caused a dose-dependent placebo-adjusted reduction in fasting TG levels of up to $76 \%$ and LDLc levels of up to $23 \%{ }^{4}$. Therefore, ANGPTL3 has been considered a potent modulator of $\mathrm{TG}^{2}$ and supports an important role of ANGPTL3 in lipid metabolism in humans.

In addition, new evidence sustains a possible role of ANGPTL3 in the progression of atherosclerosis through a lipid-independent mechanism ${ }^{6}$. Carriers of LOF mutations in ANGPTL3 associated a 34\% decrease in cardiovascular events ${ }^{7}$ and ANGPTL3 plasma concentration was associated with arterial wall thickness in humans ${ }^{8}$. Moreover, a decreased expression of ANGPTL3 in apolipoprotein E null (apoE-/-) mice was protective in the development of atherosclerosis 9 .

Familial combined hyperlipidemia (FCHL) is a common and complex inherited disorder of lipid metabolism with important environmental influences ${ }^{10}$. FCHL is characterized by elevated very low-density lipoprotein (VLDL) and/or LDL concentrations, low HDLc levels ${ }^{11}$, and frequently, reduced LPL activity ${ }^{12}$. The FCHL genetic background is mostly polygenic and associated with the variation in at least 35 different genes, including genes related to metabolic disorders such as obesity, peripheral insulin resistance, type 2 diabetes, hypertension and metabolic syndrome ${ }^{13,14}$. However, FCHL is a genetically heterogeneous syndrome and monogenic and oligogenic cases have been also described ${ }^{15-17}$. Subjects with FCHL have high predisposition to develop premature cardiovascular disease (CVD). Actually, FCHL is the most common genetic lipid abnormality found in subjects with premature coronary heart disease ${ }^{18}$. The FCHL phenotype is quite similar to that observed after

${ }^{1}$ Unidad de Lípidos, IIS Aragón, CIBERCV, Hospital Universitario Miguel Servet, Avda. Isabel La Católica 1-3, 50009 Zaragoza, Spain. ${ }^{2}$ Universidad de Zaragoza, Zaragoza, Spain. ${ }^{3}$ Instituto Aragonés de Ciencias de la Salud (IACS), Zaragoza, Spain. ${ }^{\circledR}$ email: ana.cenarro@gmail.com 


\section{Unrelated mixed hyperlipidemia \\ Triglycerides (TG) $>150 \mathrm{mg} / \mathrm{dL}$ \\ Apolipoprotein B (apoB) $>120 \mathrm{mg} / \mathrm{dL}$ \\ $n=1487$}

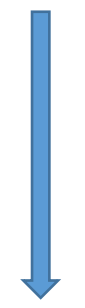

\section{Exclusion secondary causes:}

Secondary causes of hypercholesterolemia

Overweight or obesity (BMI $\geq 27.5 \mathrm{~kg} / \mathrm{m}^{2}$ )

Poorly controlled type 2 diabetes (HbA1c $>8 \%$ )

Hemochromatosis

Renal disease with glomerular filtration rate $<30 \mathrm{~mL} / \mathrm{min}$ and/or macroalbuminuria

Liver disease (alanine transaminase $>3$ times upper normal limit)

Hypothyroidism (thyroid-stimulating hormone $>6 \mathrm{mIU} / \mathrm{L}$ )

Pregnancy or estrogen treatment

Autoimmune diseases

Treatment with protease inhibitors

Alcohol consumption $>30$ grams per day

\section{Primary mixed hyperlipidemia} $n=826$

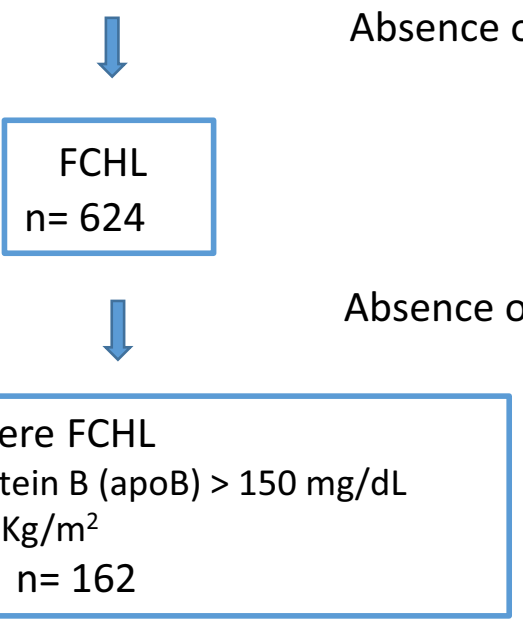

Figure 1. Flow chart of subject selection process.

ANGPTL3 administration in mice. However, the potential involvement of the ANGPTL3 gene in FCHL has not been previously analysed in contrast with the major role of a loss-of-function mutation in ANGPTL3 in the opposite situation, familial combined hypolipidemia ${ }^{19,20}$. Therefore, the aim of this study was to identify gain-offunction (GOF) genetic variants in ANGPTL3 gene in FCHL subjects and to establish the potential contribution of ANGPTL3 in the aetiology of FCHL.

\section{Material and methods}

Subjects. Cases. A total of 162 unrelated subjects, aged 23 to 82, with the clinical diagnosis of severe FCHL from Lipid Unit at Hospital Universitario Miguel Servet, Zaragoza, Spain, were selected for this study. Severe FCHL included: LDLc and TG > 90th percentile adjusted for age and sex, apolipoprotein B (apoB) $>150 \mathrm{mg} / \mathrm{dL}$, body mass index $(\mathrm{BMI})<27.5 \mathrm{~kg} / \mathrm{m}^{2}$ and at least one first-degree family member with mixed hyperlipidemia. Clinical exclusion criteria were: secondary causes of hypercholesterolemia including significant overweight or obesity (BMI $\geq 27.5 \mathrm{~kg} / \mathrm{m}^{2}$ ), poorly controlled type 2 diabetes (HbAlc $>8 \%$ ), hemochromatosis, renal disease with glomerular filtration rate $<30 \mathrm{~mL} / \mathrm{min}$ and/or macroalbuminuria, liver disease (alanine transaminase $>3$ times upper normal limit), hypothyroidism (thyroid-stimulating hormone $>6 \mathrm{mIU} / \mathrm{L}$ ), pregnancy or estrogen treatment, autoimmune diseases, treatment with protease inhibitors and alcohol consumption $>30 \mathrm{~g}$ per day (Fig. 1).

Most of the subjects included in this work had been studied previously to discard severe genetic defects in the genes regulating the LPL pathway ${ }^{21}$. Subjects with $L D L R, A P O B$ or PCSK9 functional mutations causing familial hypercholesterolemia (FH) and subjects with dysbetalipoproteinemia and the APOE2/2 genotype were excluded from the study. The lipid phenotype of FH and dysbetalipoproteinemia may overlap with FCHL and with this approach both genetic hyperlipidemias were ruled out to avoid confusion with FCHL. 


\begin{tabular}{|c|c|c|c|}
\hline ANGPTL3 & Primer sequence $5^{\prime} \rightarrow 3^{\prime}$ & Annealing temperature $\left({ }^{\circ} \mathrm{C}\right)$ & Product size (bp) \\
\hline \multirow{2}{*}{ Fragment 1} & F: CCTTACCTTTTCTGGGCAA & \multirow{2}{*}{51.5} & \multirow{2}{*}{821} \\
\hline & R: AAATGCAAATTTTCAGTGTTTTCA & & \\
\hline \multirow{2}{*}{ Fragment 2} & F: GCTGGGCTTTTTCTTTTAATTG & \multirow{2}{*}{51} & \multirow{2}{*}{496} \\
\hline & R: CTTCAGAGCCTGCAATTTT & & \\
\hline \multirow{2}{*}{ Fragment 3} & F: CCGACCAATGTCTGCTTTTT & \multirow{2}{*}{51} & \multirow{2}{*}{555} \\
\hline & R: TCAAGTCCATATTTGTATTTCTCTG & & \\
\hline \multirow{2}{*}{ Fragment 4} & F: TCCAGACTGGTGATAGAACAAG & \multirow{2}{*}{53.5} & \multirow{2}{*}{597} \\
\hline & R: GGCAATTAATGAATTTTGGCATAGT & & \\
\hline \multirow{2}{*}{ Fragment 5} & F: TCTCCTTTTCСТCTAAAATAATCTGAA & \multirow{2}{*}{52.5} & \multirow{2}{*}{596} \\
\hline & R: TGATCATTGTAAGCCGTGG & & \\
\hline \multirow{2}{*}{ Fragment 6} & F: ATGCATTATAGAAAGGATAATCAGACT & \multirow{2}{*}{52.5} & \multirow{2}{*}{700} \\
\hline & R: GAGGAAGATTAGAGGTAAAATACCTG & & \\
\hline \multirow{2}{*}{ Fragment 7} & F: ACCTCTAATCTTCCTCAGATTTTC & \multirow{2}{*}{51} & \multirow{2}{*}{599} \\
\hline & R: TTTTGATTGAGAAATGTAAACGGTA & & \\
\hline
\end{tabular}

Table 1. Primers and conditions used for ANGPTL3 amplification and sequencing. Each amplified fragment comprises the corresponding exon and its $5^{\prime}$ and $3^{\prime}$ flanking sequences, including intron-exon boundaries. $F$ forward, $R$ reverse.

Controls. We selected 165 consecutive normolipemic, unrelated subjects, aged 20-79, who underwent a medical visit at our hospital as control group. Exclusion criteria for control subjects were personal or parental history of premature cardiovascular disease (before 55 years in men and 65 years in women) or personal or parental dyslipidaemia, current acute illness, or use of drugs that might influence glucose or lipid metabolism.

In all subjects, clinical and analytical variables were registered, including personal and familial risk factors, history of cardiovascular disease and intake of drugs affecting intestinal or lipid metabolism.

All experimental protocols were approved by our local ethical committee (Comité Ético de Investigación Clínica de Aragón, CEICA, Zaragoza, Spain). Informed consent was obtained from all subjects before participating in the protocol. Samples from patients included in this study were provided by the Biobank of the Aragon Health System (PT17/0015/0039), integrated in the Spanish National Biobanks Network, and they were processed following standard operating procedures with the appropriate approval of the Ethics and Scientific Committees.

Biochemical analysis. Ethylenediaminetetraacetic acid (EDTA) plasma and serum samples were collected from all participants after at least $10 \mathrm{~h}$ fasting, without lipid-lowering drugs for $>5$ weeks, to obtain baseline biochemical characteristics. Total cholesterol (TC) and TG measurements were performed with commercially available diagnostic kits (Boehringer Mannheim, Germany), in a laboratory participating in a lipid standardisation programme. HDLc was measured directly by an enzymatic reaction using cholesterol oxidase (UniCel DxC 800; Beckman Coulter Inc., Brea, California, USA). ApoA1, apoB and lipoprotein(a ${ }^{22}$ were determined by IMMAGE kinetic immunonephelometry (Beckman Coulter Inc., Brea, California, USA). LDLc was calculated using the Friedewald's formula ${ }^{23}$. All methods were carried out in accordance with guidelines and regulations of Spanish Society of Clinical Biochemistry.

Genetic analysis. DNA was isolated from EDTA blood samples using the KingFisher Duo Prime System (Thermo Fisher Scientific). A previously described protocol for sequencing the exon 4 of $A P O E$ gene $^{24}$ was used for disclosing $A P O E 2 / 2$ genotype or functional mutations in exon 4 of the $A P O E$ gene in order to rule out carrier subjects. Moreover, $L D L R, A P O B$ and $P C S K 9$ genes were analysed for functional mutations with Lipochip platform (Progenika Grifols, Spain) ${ }^{25}$ in order to rule out subjects with any pathogenic mutation in these genes.

ANGPTL3 gene (NM_014495.4) was amplified in 7 fragments by polymerase chain reaction with primers showed in Table 1. Each amplified fragment comprised the corresponding exon and its $5^{\prime}$ and $3^{\prime}$ flanking sequences, including intron-exon boundaries. After purification with ExoSap-IT (USB), amplified fragments were sequenced by the Sanger method ${ }^{26}$ using the BigDye 3.1 sequencing kit (Applied Biosystems) in an automated ABI 3500xL sequencer (Applied Biosystems). DNA sequences were analysed using Variant Reporter software (Applied Biosystems).

To evaluate the pathogenicity of new identified genetic variants, we used PredictSNP2 ${ }^{27}$. The effect of variants in potential splicing sites was predicted with FruitFly ${ }^{28}$. To compare the frequency of identified variants with that of the general population, we compiled the allele frequencies of identified variants from the 1000 Genomes Project ${ }^{29}$ and genome aggregation data base (gnomAD) $)^{30}$. ClinVar database was used for additional information about genomic variation and its relationship to human health ${ }^{31}$. Finally, information about microRNAs was obtained from PolymiRTS Database $3.0^{32}$. All methods were carried out in accordance with guidelines and regulations of Spanish Society of Human Genetics.

Statistical analysis. Analyses were performed using statistical computing software R version 3.5.0 $0^{33}$. The level of significance was set at $P<0.05$. The distribution of the variables was analysed by the Shapiro test. Quan- 


\begin{tabular}{|c|c|c|c|}
\hline & FCHL subjects $n=162$ & Normolipemic controls $n=165$ & $p$ \\
\hline Men, n (\%) & $98(60.5)$ & $78(47.3)$ & 0.022 \\
\hline Age (years) & $50.4 \pm 11.4$ & $38.5 \pm 14.7$ & $<0.001$ \\
\hline Body Mass Index $\left(\mathrm{kg} / \mathrm{m}^{2}\right)$ & $25.6(24.2-26.5)$ & $23.6(21.4-26.6)$ & $<0.001$ \\
\hline Total Cholesterol (mg/dL) & $312 \pm 36.1$ & $170 \pm 21.0$ & $<0.001$ \\
\hline Triglycerides (mg/dL) & $277(232-373)$ & $64.0(49.0-93.0)$ & $<0.001$ \\
\hline LDL cholesterol (mg/dL) & $204(183-230)$ & $108(91.8-117)$ & $<0.001$ \\
\hline HDL cholesterol (mg/dL) & $48.5 \pm 12.0$ & $55.7 \pm 11.4$ & 0.015 \\
\hline Apolipoprotein A1 (mg/dL) & $147 \pm 25.0$ & $147 \pm 27.4$ & 0.930 \\
\hline Apolipoprotein B (mg/dL) & $167(165-190)$ & $83.0(72.0-91.0$ & $<0.001$ \\
\hline Lipoprotein(a), (mg/dL) & $39.1(10.3-80.8)$ & $16.2(7.79-44.5)$ & 0.003 \\
\hline Glucose (mg/dL) & $93.0(86.0-103)$ & $85.0(80.0-92.0)$ & $<0.001$ \\
\hline HbAlc (\%) & $5.50(5.30-5.80)$ & $5.20(5.00-5.40)$ & $<0.001$ \\
\hline Type 2 diabetes, $\mathrm{n}(\%)$ & $13(8.02)$ & $2(1.21)$ & 0.009 \\
\hline Hypertension, n (\%) & $30(18.5)$ & $10(6.06)$ & 0.001 \\
\hline Cardiovascular disease, $\mathrm{n}(\%)$ & $7(4.32)$ & 0 & 0.016 \\
\hline \multicolumn{4}{|l|}{ Tobacco, n (\%) } \\
\hline Non smoker & $51(31.5)$ & $96(58.1)$ & \multirow{3}{*}{$<0.001$} \\
\hline Smoker & $70(43.2)$ & $31(18.8)$ & \\
\hline Former smoker & $40(24.7)$ & $28(16.7)$ & \\
\hline \multicolumn{4}{|c|}{ Apolipoprotein E genotype, n (\%) } \\
\hline E3/3 & $113(69.8)$ & $109(66.1)$ & \multirow{6}{*}{0.035} \\
\hline E3/2 & $9(5.56)$ & $25(15.2)$ & \\
\hline $\mathrm{E} 2 / 2$ & 0 & 0 & \\
\hline E3/4 & $31(19.1)$ & $25(15.2)$ & \\
\hline $\mathrm{E} 4 / 4$ & $6(3.70)$ & $2(1.21)$ & \\
\hline E2/4 & 3 & 4 & \\
\hline
\end{tabular}

Table 2. Clinical and biochemical characteristics in FCHL subjects and normolipemic controls. Quantitative continuous variables are expressed as mean \pm standard deviation or median [percentile 25-75]. Student's $t$ or Mann-Whitney tests were used to assess differences between two groups. Quantitative categorical variables are expressed as $\mathrm{n}(\%)$ and statistical differences were assessed by Chi-squared.

titative variables with a normal distribution were expressed as mean \pm standard deviation and were analysed by the Student $t$ test. Variables with a skewed distribution were expressed as medians and interquartile ranges and were analysed with the Mann-Whitney $U$ test. Qualitative variables were expressed as percentages and were analysed by the Chi squared test.

\section{Results}

Study subjects. The main clinical and biochemical characteristics of both studied groups (162 FCHL subjects and 165 normolipemic controls) are presented in Table 2. FCHL subjects showed higher predominance of males $(60.5 \%)$ and were significantly older than normolipemic subjects $(P=0.022$ and $P<0.001$, respectively). Compared with normolipemic controls, FCHL subjects had significantly higher values of BMI, TC, TG, LDLc, apoB and lipoprotein(a) $(P<0.001, P<0.001, P<0.001, P<0.001, P<0.001$ and $P=0.003$, respectively). FCHL subjects presented higher prevalence of hypertension, type 2 diabetes and CVD than normolipemic subjects $(P=0.009, P=0.001$ and $P=0.016$, respectively). The $A P O E$ genotype distribution was homogenous between both cohorts, being E3/3 genotype the most frequent in both groups, although E3/2 genotype had a lower frequency in FCHL subjects (5.56\%) in contrast to normolipemic subjects (15.2\%).

ANGPTL3 genetic variants. Table 3 shows all variants in the ANGPTL3 gene identified in both groups. A total of 16 genetic variants, four of them not previously described, were identified by sequencing analysis. Only four of them (c.607-109T>C, c.607-47_607-46delGT, c.835+41C >A and c. ${ }^{\star 52}{ }^{\star} 60$ del) presented significantly different allele frequency in normolipemic group than in FCHL subjects $(P=0.020, P=0.031, P=0.043$ and $P<0.001$, respectively). Out of the 16 variants, seven variants were located in the coding region (c.379C $>$ T, c. $565 \mathrm{~T}>\mathrm{C}, \mathrm{c} .961 \mathrm{~T}>\mathrm{A}, \mathrm{c} .1003 \mathrm{~T}>\mathrm{C}, \mathrm{c} .1028 \mathrm{~A}>\mathrm{G}, \mathrm{c} .1089 \mathrm{~T}>\mathrm{G}$ and c.1122G $>\mathrm{A}$ ), and three of them were missense variants: p. (Leu127Phe), p.(Tyr321Asn) and p.(His343Arg), but only p.(Leu127Phe) was described as deleterious by bioinformatics analysis. The other four variants located in the coding region, p.(Leu189Leu), p.(Leu335Leu), p.(Val363Val) and p.(Pro374Pro) were synonymous variants. Seven variants were located in the intronic region, c. $496-88 \mathrm{~T}>\mathrm{G}, \quad$ c.607-120A $>\mathrm{G}, \quad$ c.607-109T $>$ C,$\quad$ c.607-47_607-46delGT, c.835+41C>A, c.1198+111G $>\mathrm{A}$ and c.1198+140T $>$ C. All of them were described as benign or not splicing change affected by the bioinformatics analysis. Nevertheless, three of them, c.607-109T>C, c.607-47_607-46delGT and c.835+41C>A, presented sig- 


\begin{tabular}{|c|c|c|c|c|c|c|c|c|c|c|c|c|}
\hline \multirow[b]{2}{*}{ Variant } & \multirow[b]{2}{*}{ Location } & \multirow[b]{2}{*}{$\begin{array}{l}\text { Nucleotide } \\
\text { change }\end{array}$} & \multirow[b]{2}{*}{$\begin{array}{l}\text { Protein } \\
\text { change }\end{array}$} & \multicolumn{2}{|c|}{ Bioinformatics analysis } & \multicolumn{2}{|c|}{$\begin{array}{l}\text { Allele frequency in the } \\
\text { general population }\end{array}$} & \multicolumn{3}{|c|}{ Allele frequency in our study } & \multirow[b]{2}{*}{$\begin{array}{l}\text { ACMG } \\
\text { classification }^{\mathrm{e}}\end{array}$} & \multirow[b]{2}{*}{ MicroRNAs $^{f}$} \\
\hline & & & & $\begin{array}{l}\text { PredictSNP2 }^{a} \\
\text { (probability) }\end{array}$ & FruitFly ${ }^{b}$ & GnomAD $^{c}$ & $\begin{array}{l}1000 \\
\text { Genomes } \\
\text { Project }^{\mathrm{d}}\end{array}$ & $\begin{array}{l}\text { Normolipemic } \\
\text { subjects }\end{array}$ & $\begin{array}{l}\text { FCHL } \\
\text { subjects }\end{array}$ & $p$ & & \\
\hline rs72649573 & Exon 1 & c. $379 \mathrm{C}>\mathrm{T}$ & $\begin{array}{l}\text { p. } \\
\text { (Leu127Phe) }\end{array}$ & $\begin{array}{l}\text { Deleterious } \\
(82 \%)\end{array}$ & NA & 0.00711 & 0.0020 & 0.000 & 0.003 & 0.313 & Benign $^{g}$ & NR \\
\hline- & Intron 1 & c. $496-88 \mathrm{~T}>\mathrm{G}$ & NA & Neutral (88\%) & $\begin{array}{l}\text { Not } \\
\text { splicing } \\
\text { change }\end{array}$ & - & - & 0.000 & 0.003 & 0.313 & - & - \\
\hline rs111414963 & Exon 2 & c. $565 \mathrm{~T}>\mathrm{C}$ & $\begin{array}{l}\text { p. } \\
\text { (Leu189Leu) }\end{array}$ & Neutral $(88 \%)$ & $\begin{array}{l}\text { Not } \\
\text { splicing } \\
\text { change }\end{array}$ & 0.00025 & 0.0008 & 0.003 & 0.000 & 0.313 & Likely benign & NR \\
\hline rs531071581 & Intron 2 & c. $607-120 A>G$ & NA & Neutral (88\%) & $\begin{array}{l}\text { Not } \\
\text { splicing } \\
\text { change }\end{array}$ & 0.00013 & 0.0006 & 0.000 & 0.003 & 0.313 & - & NR \\
\hline rs72649576 & Intron 2 & c. $607-109 \mathrm{~T}>\mathrm{C}$ & NA & Neutral (88\%) & $\begin{array}{l}\text { Not } \\
\text { splicing } \\
\text { change }\end{array}$ & 0.01079 & 0.0042 & 0.024 & 0.003 & 0.020 & - & NR \\
\hline rs72649577 & Intron 2 & $\begin{array}{l}\text { c.607-47_607- } \\
46 \text { delGT }\end{array}$ & NA & Neutral (88\%) & NA & 0.02222 & 0.0136 & 0.022 & 0.003 & 0.031 & - & NR \\
\hline rs185472483 & Intron 3 & c. $835+41 \mathrm{C}>\mathrm{A}$ & NA & - & $\begin{array}{l}\text { Not } \\
\text { splicing } \\
\text { change }\end{array}$ & 0.00032 & 0.0006 & 0.000 & 0.012 & 0.043 & - & NR \\
\hline rs747725081 & Exon 6 & c. $961 \mathrm{~T}>\mathrm{A}$ & $\begin{array}{l}\text { p. } \\
\text { (Tyr321Asn) }\end{array}$ & Neutral (88\%) & NA & NR & NR & 0.000 & 0.003 & 0.313 & - & NR \\
\hline rs12563308 & Exon 6 & c. $1003 \mathrm{~T}>\mathrm{C}$ & $\begin{array}{l}\text { p. } \\
\text { (Leu335Leu) }\end{array}$ & Neutral (88\%) & NA & 0.03550 & 0.0559 & 0.003 & 0.003 & 0.989 & VUSg & NR \\
\hline rs199555921 & Exon 6 & c. $1028 \mathrm{~A}>\mathrm{G}$ & $\begin{array}{l}\text { p. } \\
\text { (His343Arg) }\end{array}$ & Neutral (89\%) & NA & 0.00016 & NR & 0.003 & 0.000 & 0.321 & - & NR \\
\hline rs763259225 & Exon 6 & c. $1089 \mathrm{~T}>\mathrm{G}$ & p.(Val363Val) & Neutral (96\%) & NA & NR & NR & 0.003 & 0.000 & 0.321 & - & NR \\
\hline rs145086916 & Exon 6 & c. $1122 \mathrm{G}>\mathrm{A}$ & $\begin{array}{l}\text { p.(Pro- } \\
\text { 374Pro) }\end{array}$ & Neutral (96\%) & NA & 0.00077 & 0.0006 & 0.003 & 0.000 & 0.321 & - & NR \\
\hline rs72651034 & Intron 6 & c. $1198+111 \mathrm{G}>\mathrm{A}$ & NA & - & $\begin{array}{l}\text { Not } \\
\text { splicing } \\
\text { change }\end{array}$ & NR & NR & 0.003 & 0.003 & 0.989 & - & NR \\
\hline rs908541128 & Intron 6 & c. $1198+140 \mathrm{~T}>\mathrm{C}$ & NA & - & $\begin{array}{l}\text { Not } \\
\text { splicing } \\
\text { change }\end{array}$ & 0.000 & 0.000 & 0.003 & 0.000 & 0.321 & - & NR \\
\hline rs 34483103 & 3'UTR & c. ${ }^{*} 52 \_* 60 \mathrm{del}$ & NA & - & NA & 0.33531 & 0.3484 & 0.276 & 0.102 & $<0.001$ & - & $\begin{array}{l}\text { hsa-miR- } \\
151 a-3 p \\
\text { hsa-miR-7702 }\end{array}$ \\
\hline- & 3'UTR & c. ${ }^{\star} 76 \mathrm{~T}>\mathrm{G}$ & NA & - & NA & - & - & 0.000 & 0.003 & 0.313 & - & - \\
\hline
\end{tabular}

Table 3. Frequency and bioinformatics analysis of identified variants in ANGPTL3 in FCHL cases and controls. NR not reported, NA not applicable, VUS variant of uncertain significance. ${ }^{a}$ PredictSNP2 uses CADD, DANN, FATHMM and Funseq2 as predictors. ${ }^{b}$ FruitFly. New prediction score 0.87 (wild type score 0.89 ). ${ }^{\mathrm{c}}$ GnomAD. https://gnomad.broadinstitute.org/ d 1000 Genomes Project Consortium, Abecasis GR, Auton A, Books LD et al. An integrated map of genetic variation from 1092 human genomes. Nature 2012;491:56-65. ${ }^{\text {e}}$ Richards S, Aziz N, Bale S, Bick D, Das S, Gastier-Foster J, Grody WW, Hegde M, Lyon E, Spector E, Voelkerding K, Rehm HL; ACMG Laboratory Quality Assurance Committee. Standards and guidelines for the interpretation of sequence variants: a joint consensus recommendation of the American College of Medical Genetics and Genomics and the Association for Molecular Pathology. Genet Med. 2015 May;17(5):405-24. https://doi.org/10.1038/gim.2015.30. Epub 2015 Mar 5. PMID: 25741868; PMCID: PMC4544753. fPolymiRTS Database 3.0: http://compbio.uthsc.edu/miRSNP/ ${ }^{\text {g}}$ Tikka A, Metso J, Jauhiainen M. ANGPTL3 serum concentration and rare genetic variants in Finnish population. Scand J Clin Lab Invest. 2017;77:601-609.

nificantly higher allele frequency in FCHL subjects than in the normolipemic group. Finally, two variants were located in the $3{ }^{\prime} \mathrm{UTR}, \mathrm{c} .{ }^{\star} 52{ }_{-}{ }^{\star} 60 \mathrm{del}$ and $\mathrm{c} .{ }^{\star} 76 \mathrm{~T}>\mathrm{G}$. One of them, c. ${ }^{\star} 52_{-}{ }^{*} 60 \mathrm{del}$, showed significantly higher allele frequency in the normolipemic group than in FCHL subjects.

\section{Discussion}

We have studied the possible contribution of the gene encoding ANGPTL3 in the aetiology of FCHL. Our hypothesis was that some rare gain-of-function variants could have a major effect on the disease or, on the contrary, that common variants with minor effect on ANGPTL3 function could be in different frequency with respect to the general population. The results of our study do not support the first possibility, since the identified variants are not predictive of relevant functional changes in the protein. There are no previous ANGPTL3 sequencing studies looking for GOF mutations in subjects with FCHL. At least 5 different loci have been associated with rare cases of monogenic FCHL: $L D L R^{16,17}, L P L^{15}, A P O E^{34}, P C S K 9^{35}$ and $A P O A 5^{36,37}$, but ANGPTL3 
does not appear to be associated with this form of FCHL nor familial hypercholesterolemia (FH). Although FH and FCHL are different phenotypes, there is some degree of overlap between the two entities since they share many clinical aspects. Studies in subjects with genetic hypercholesterolemia of unknown origin suggestive of FH have also failed to detect causal mutations in ANGPTL3. We have not found any severe mutation neither in cases nor in controls in the total of 654 alleles investigated. This leads us to think about how well preserved is this gene probably related to the importance of this gene in human metabolism.

These results contrast with the role of ANGPTL3 in the lipid phenotype called familial combined hypolipidemia (FHBL2, OMIM \#605019) ${ }^{20}$, in which LOF mutations in ANGPTL3 are responsible of reduced plasma levels of TC, TG, VLDL cholesterol, LDLc, apoB, and free fatty acids, just the opposite lipid profile found in FCHL. Furthermore, FCHL and familial combined hypolipidemia share abnormal hepatic VLDL secretion rates as the main mechanism of the lipid abnormalities, being increased in $\mathrm{FCHL}^{38,39}$ and decreased in familial combined hypolipidemia ${ }^{40}$.

Most cases of FCHL are considered as a complex disease with interaction of polygenes or multiple allele relationships with effect on TC, TG and environmental factors, mainly obesity and diets rich in saturated fat. ANGPTL3 genetic variation has not been associated with FCHL or mixed hyperlipidemia in genome-wide association studies (GWAS) ${ }^{13,41}$. Similar conclusions can be drawn from large-scale deep-coverage whole-genome sequencing ${ }^{42}$. Our study cannot rule out that the genetic variation in ANGPTL3 participates in the final phenotype of polygenic forms of FCHL. We found four variants with different allele frequency in FCHL subjects and in normolipemic controls: c.607-109T>C, c.607-47_607-46delGT, c.835+41C>A and c. ${ }^{\star 52}{ }_{-}^{*} 60 \mathrm{del}$. The first three are located in intron regions and the in silico analysis does not predict any splicing change with clinical significance, so their contribution to FCHL seems unlikely. The variant c. ${ }^{*} 52_{-}{ }^{*} 60 \mathrm{del}$, located in $3^{\prime} \mathrm{UTR}$, presented statistically significant differences in allelic frequencies between FCHL subjects and normolipemic controls: 0.276 and 0.102 , respectively $(\mathrm{P}<0.001)$. This variant has been previously associated with two microRNAs, hsa-miR$151 \mathrm{a}-3 \mathrm{p}$ and hsa-miR-7702, modulators of gene expression ${ }^{32}$. However, this is a very frequent genetic variant in the general population and this variation has not been previously associated with cholesterol and triglyceride concentrations ${ }^{43,44}$, so its implication in the FCHL pathogenesis is unlikely, although it should be confirmed in future studies.

In summary, no GOF mutations in ANGPTL3 were present in a large group of unrelated subjects with FCHL. Our results do not support a substantial role of ANGPTL3 in FCHL.

Received: 22 December 2020; Accepted: 9 March 2021

Published online: 26 March 2021

\section{References}

1. Conklin, D. et al. Identification of a mammalian angiopoietin-related protein expressed specifically in liver. Genomics 62, 477-482 (1999).

2. Shimizugawa, T. et al. ANGPTL3 decreases very low density lipoprotein triglyceride clearance by inhibition of lipoprotein lipase. J. Biol. Chem. 277, 33742-33748 (2002).

3. Shimamura, M. et al. Angiopoietin-like protein3 regulates plasma HDL cholesterol through suppression of endothelial lipase. Arterioscler. Thromb. Vasc. Biol. 27, 366-372 (2007).

4. Dewey, F. E. et al. Genetic and pharmacologic inactivation of ANGPTL3 and cardiovascular disease. N. Engl. J. Med. 377, 211-221 (2017).

5. Ono, M. et al. Protein region important for regulation of lipid metabolism in angiopoietin-like 3 (ANGPTL3): ANGPTL3 is cleaved and activated in vivo. J. Biol. Chem. 278, 41804-41809 (2003).

6. Korstanje, R. et al. Locating Ath8, a locus for murine atherosclerosis susceptibility and testing several of its candidate genes in mice and humans. Atherosclerosis 177, 443-450 (2004).

7. Stitziel, N. O. et al. ANGPTL3 deficiency and protection against coronary artery disease. J. Am. Coll. Cardiol. 69, 2054-2063 (2017).

8. Hatsuda, S. et al. Association between plasma angiopoietin-like protein 3 and arterial wall thickness in healthy subjects. J. Vasc. Res. 44, 61-66 (2007).

9. Ando, Y. et al. A decreased expression of angiopoietin-like 3 is protective against atherosclerosis in apoE-deficient mice. J. Lipid Res. 44, 1216-1223 (2003).

10. Goldstein, J. L., Schrott, H. G., Hazzard, W. R., Bierman, E. L. \& Motulsky, A. G. Hyperlipidemia in coronary heart disease. II. Genetic analysis of lipid levels in 176 families and delineation of a new inherited disorder, combined hyperlipidemia. J. Clin. Invest. 52, 1544-1568 (1973).

11. Gaddi, A., Galetti, C., Pauciullo, P. \& Arca, M. Familial combined hyperlipoproteinemia: experts panel position on diagnostic criteria for clinical practice. Committee of experts of the Atherosclerosis and Dysmetabolic Disorders Study Group. Nutr. Metab. Cardiovasc. Dis. NMCD 9, 304-311 (1999).

12. Babirak, S. P., Brown, B. G. \& Brunzell, J. D. Familial combined hyperlipidemia and abnormal lipoprotein lipase. Arterioscler. Thromb. 12(10), 1176-1183. https://doi.org/10.1161/01.atv.12.10.1176 (1992).

13. Brouwers, M. C. G. J., van Greevenbroek, M. M. J., Stehouwer, C. D. A., de Graaf, J. \& Stalenhoef, A. F. H. The genetics of familial combined hyperlipidaemia. Nat. Rev. Endocrinol. 8, 352-362 (2012).

14. Veerkamp, M. J., de Graaf, J. \& Stalenhoef, A. F. H. Role of insulin resistance in familial combined hyperlipidemia. Arterioscler. Thromb. Vasc. Biol. 25, 1026-1031 (2005).

15. Yang, W. S., Nevin, D. N., Peng, R., Brunzell, J. D. \& Deeb, S. S. A mutation in the promoter of the lipoprotein lipase (LPL) gene in a patient with familial combined hyperlipidemia and low LPL activity. Proc. Natl. Acad. Sci. 92, 4462-4466 (1995).

16. Civeira, F. et al. Frequency of low-density lipoprotein receptor gene mutations in patients with a clinical diagnosis of familial combined hyperlipidemia in a clinical setting. J. Am. Coll. Cardiol. 52, 1546-1553 (2008).

17. Minicocci, I. et al. Contribution of mutations in low density lipoprotein receptor (LDLR) and lipoprotein lipase (LPL) genes to familial combined hyperlipidemia (FCHL): A reappraisal by using a resequencing approach. Atherosclerosis 242, 618-624 (2015).

18. Austin, M. A. et al. Cardiovascular disease mortality in familial forms of hypertriglyceridemia: A 20 -year prospective study. Circulation 101, 2777-2782 (2000).

19. Di Costanzo, A. et al. Clinical and biochemical characteristics of individuals with low cholesterol syndromes: A comparison between familial hypobetalipoproteinemia and familial combined hypolipidemia. J. Clin. Lipidol. 11, 1234-1242 (2017). 
20. Arca, M., D'Erasmo, L. \& Minicocci, I. Familial combined hypolipidemia: Angiopoietin-like protein-3 deficiency. Curr. Opin. Lipidol. 31, 41-48 (2020).

21. De Castro-Orós, I. et al. Common genetic variants contribute to primary hypertriglyceridemia without differences between familial combined hyperlipidemia and isolated hypertriglyceridemia. Circ. Cardiovasc. Genet. 7, 814-821 (2014).

22. Marcovina, S. M. et al. Use of a reference material proposed by the International Federation of Clinical Chemistry and Laboratory Medicine to evaluate analytical methods for the determination of plasma lipoprotein(a). Clin. Chem. 46, 1956-1967 (2000).

23. Friedewald, W. T., Levy, R. I. \& Fredrickson, D. S. Estimation of the concentration of low-density lipoprotein cholesterol in plasma, without use of the preparative ultracentrifuge. Clin. Chem. 18, 499-502 (1972).

24. Bea, A. M. et al. Lipid-lowering response in subjects with the p.(Leu167del) mutation in the APOE gene. Atherosclerosis 282, 143-147 (2019).

25. Palacios, L. et al. Molecular characterization of familial hypercholesterolemia in Spain. Atherosclerosis 221, 137-142 (2012)

26. Sanger, F., Nicklen, S. \& Coulson, A. R. DNA sequencing with chain-terminating inhibitors. Proc. Natl. Acad. Sci. U. S. A. 74, 5463-5467 (1977).

27. Bendl, J. et al. PredictSNP2: A unified platform for accurately evaluating SNP effects by exploiting the different characteristics of variants in distinct genomic regions. PLoS Comput. Biol. 12, e1004962 (2016).

28. Reese, M. G., Eeckman, F. H., Kulp, D. \& Haussler, D. Improved splice site detection in Genie. J. Comput. Biol. J. Comput. Mol. Cell Biol. 4, 311-323 (1997).

29. 1000 Genomes Project Consortium et al. An integrated map of genetic variation from 1,092 human genomes. Nature 491, 56-65 (2012).

30. Karczewski, K. J. et al. Variation across 141,456 human exomes and genomes reveals the spectrum of loss-of-function intolerance across human protein-coding genes. http://biorxiv.org/lookup/. https://doi.org/10.1101/531210 (2019).

31. ClinVar. https://www.ncbi.nlm.nih.gov/clinvar/.

32. Bhattacharya, A., Ziebarth, J. D. \& Cui, Y. PolymiRTS Database 3.0: linking polymorphisms in microRNAs and their target sites with human diseases and biological pathways. Nucleic Acids Res. 42, D86-D91 (2014).

33. Team, R. C. R Foundation for Statistical Computing; Vienna, Austria: 2014. R Lang. Environ. Stat. Comput. 2013 (2018).

34. Solanas-Barca, M. et al. Apolipoprotein E gene mutations in subjects with mixed hyperlipidemia and a clinical diagnosis of familial combined hyperlipidemia. Atherosclerosis 222, 449-455 (2012).

35. Abifadel, M. et al. A PCSK9 variant and familial combined hyperlipidaemia. J. Med. Genet. 45, 780-786 (2008).

36. van der Vleuten, G. M. et al. Haplotype analyses of the APOA5 gene in patients with familial combined hyperlipidemia. Biochim. Biophys. Acta 1772, 81-88 (2007).

37. Di Taranto, M. D. et al. Association of USF1 and APOA5 polymorphisms with familial combined hyperlipidemia in an Italian population. Mol. Cell. Probes 29, 19-24 (2015).

38. Baila-Rueda, L. et al. Cholesterol oversynthesis markers define familial combined hyperlipidemia versus other genetic hypercholesterolemias independently of body weight. J. Nutr. Biochem. 53, 48-57 (2018).

39. van Himbergen, T. M. et al. Familial combined hyperlipidemia is associated with alterations in the cholesterol synthesis pathway. Arterioscler. Thromb. Vasc. Biol. 30, 113-120 (2010).

40. Hess, A. L. et al. Analysis of circulating angiopoietin-like protein 3 and genetic variants in lipid metabolism and liver health: The DiOGenes study. Genes Nutr. 13, 7 (2018).

41. Ripatti, P. et al. The contribution of GWAS Loci in Familial Dyslipidemias. PLOS Genet. 12, e1006078 (2016).

42. Natarajan, P. et al. Deep-coverage whole genome sequences and blood lipids among 16,324 individuals. Nat. Commun. 9, 3391 (2018).

43. Surakka, I. et al. The impact of low-frequency and rare variants on lipid levels. Nat. Genet. 47, 589-597 (2015).

44. UK10K consortium. The UK10K project identifies rare variants in health and disease. Nature 526, 82-90 (2015).

\section{Acknowledgements}

This work was supported by Grants from Gobierno de Aragon, B14-7R, Spain; Spanish Ministry of Economy and Competitiveness PI15/01983, PI18/01777 and CIBERCV. We want to particularly acknowledge the patients and the Biobank of the Aragon Health System (PT17/0015/0039) integrated in the Spanish National Biobanks Network for their collaboration.

\section{Author contributions}

A.M.B.: Data acquisition, methodology, writing-original draft. E.F.-M.: Data acquisition. V.M.-B., E.J. and I.G.-R.: Data acquisition and methodology. A.C.: Conceptualization, Formal analysis, Writing-original draft, Supervision. F.C.: Conceptualization, Funding acquisition, Project administration, writing-original draft, Supervision. I.L.-M.: Data acquisition and methodology, formal analysis and writing-original draft. All authors have reviewed and approved the final version of the manuscript.

\section{Competing interests}

The authors declare no competing interests.

\section{Additional information}

Correspondence and requests for materials should be addressed to A.C.

Reprints and permissions information is available at www.nature.com/reprints.

Publisher's note Springer Nature remains neutral with regard to jurisdictional claims in published maps and institutional affiliations. 
(c) (i) Open Access This article is licensed under a Creative Commons Attribution 4.0 International cc) License, which permits use, sharing, adaptation, distribution and reproduction in any medium or format, as long as you give appropriate credit to the original author(s) and the source, provide a link to the Creative Commons licence, and indicate if changes were made. The images or other third party material in this article are included in the article's Creative Commons licence, unless indicated otherwise in a credit line to the material. If material is not included in the article's Creative Commons licence and your intended use is not permitted by statutory regulation or exceeds the permitted use, you will need to obtain permission directly from the copyright holder. To view a copy of this licence, visit http://creativecommons.org/licenses/by/4.0/.

(C) The Author(s) 2021 